\title{
Dock Leaf Beetle, Gastrophysa viridula Deg., Herbivory on the Mossy Sorrel, Rumex confertus Willd: Induced Plant Volatiles and Beetle Orientation Responses
}

\author{
Dariusz Piesik (Corresponding author) \\ Department of Applied Entomology, University of Technology and Life Sciences \\ 20 Kordeckiego St., 85 - 225 Bydgoszcz, Poland \\ Tel: 48-52-374-9361 E-mail: piesik@utp.edu.pl \\ Anna Wenda-Piesik \\ Department of Plant Growth Principles and Experimental Methodology \\ University of Technology and Life Sciences \\ 20 Kordeckiego St., 85 - 225 Bydgoszcz, Poland \\ Magdalena Ligor \\ Chair of Environmental Chemistry and Bioanalytics \\ Faculty of Chemistry, Nicolaus Copernicus University \\ 7 Gagarina St., 87-100 Toruń, Poland \\ Bogusław Buszewski \\ Chair of Environmental Chemistry and Bioanalytics \\ Faculty of Chemistry, Nicolaus Copernicus University \\ 7 Gagarina St., 87-100 Toruń, Poland \\ Kevin J. Delaney \\ Pest Management Research Unit, USDA-ARS NPARL \\ 1500 N. Central Ave., Sidney, MT 59270, USA
}

Received: April 13, 2011

Accepted: May 9, $2011 \quad$ Online Published: December 1, 2011

doi:10.5539/jas.v4n1p97

URL: http://dx.doi.org/10.5539/jas.v4n1p97

\begin{abstract}
The invasive weed Rumex confertus Willd. (mossy sorrel) is fed upon and severely defoliated by Gastrophysa viridula Deg. (dock leaf beetle). We report volatile organic compound (VOC) induction when one leaf on $R$. confertus was damaged by $G$. viridula adults to better understand plant responses to herbivory. The $R$. confertus volatile blend induced by $G$. viridula feeding included three green leaf volatiles (GLVs; (Z)-3-hexenal, (Z)-3-hexen-1-ol, (Z)-3-hexen-1-yl acetate) and terpenes (linalool, ß-caryophyllene, ß-farnesene). Overall, R. confertus that had been damaged by $G$. viridula released far greater concentrations of these six VOCs than control plants. Male and female of $G$. viridula had no significant attraction or repulsion to (Z)-3-hexen-1-ol or ß-caryophyllene. A significantly greater proportion of female and male beetles were attracted to (Z)-3-hexenal (5 $\left.\mathrm{ng} \cdot \mathrm{min}^{-1}=300 \mathrm{ng} \cdot \mathrm{hr}^{-1}\right)$ and $(\mathrm{Z})-3$-hexen-1-yl acetate $\left(5\right.$ and $\left.25 \mathrm{ng} \cdot \mathrm{min}^{-1}\right)$, in the range of induced concentrations emitted by a single injured leaf.
\end{abstract}


Keywords: Dock leaf beetles, Mossy sorrel, Odours, VOCs

\section{Introduction}

Plants are attacked by many herbivorous insects (Thaler et al., 2002), as almost half of described insect species are herbivorous (Schoonhoven et al., 2005). However, plants are not merely passive to the attack of herbivores. In response to herbivory plants evolved many defences to protect themselves (Baldwin et al., 2001; Schoonhoven et al., 2005). One mechanism of plant defence is induction of volatile organic compounds (VOCs), which can directly deter herbivores (De Moraes et al., 2001) or indirectly act by attracting natural enemies of the herbivore (Heil, 2008). It is thought that VOC induction helps reduce herbivory to an injured plant and help fitness (compared to non-VOC emitting injured plants), though the ecological consequences of VOC induction are complex (Dicke \& Baldwin, 2010).

One group of plants with strong habitat expansion and high population growth characteristics are dock and sorrel weeds, Rumex spp., due to very high seed numbers (Cavers \& Harper, 1964). These weedy invasive plants are harmful because they degrade their habitats and locally dominate or even replace native plants. Also, Rumex spp. can reduce the quantity and quality of cattle fodder in fields, having economic consequences. One invasive weed species of interest is mossy sorrel, $R$. confertus, which has a rapid rate of spread.

Thus, a search for potential biological control agents exists for $R$. confertus (Martinkova \& Honek, 2004). The most damaging phytophagous insect occurring on $R$. confertus is the dock leaf beetle, Gastrophsa viridula L. (Chrysomelidae) (Martinova \& Honek, 2004). Adults, but especially the larvae, can completely defoliate dock plants when at high densities (Honek et al., 2003, Piesik \& Wenda-Piesik, 2005). Due to having few predators, feeding specialization on the target weed, and a short life cycle, $G$. viridula is considered an excellent biological control candidate for $R$. confertus.

In the present study, we identified VOCs induced in $R$. confertus by G. viridula herbivory. Subsequently, we used y-tube behavioural experiments to test dose response of $G$. viridula to two green leaf volatiles (GLVs) and three terpenes that were induced by $R$. confertus, where each VOC was tested individually. Determining VOCs induced by $R$. confertus from G. viridula herbivory and how G. viridula responses to induced VOCs can help in the study of direct and indirect $R$. confertus defences, and can contribute to an improved understanding of a plant-insect interaction involving an invasive weed and a potential biological control agent.

\section{Material and methods}

\subsection{Plant culture}

Experiments were performed at the Plant Growth Center - PGC, (University of Technology and Life Sciences, Bydgoszcz, Poland) in 2010.

$R$. confertus plants were planted in a greenhouse with supplemental light and ambient humidity. The photoperiod was $16 \mathrm{~L}: 8 \mathrm{D}$. Daytime temperature was $22 \pm 2^{\circ} \mathrm{C}$ and the overnight temperature was $18 \pm 2^{\circ} \mathrm{C}$. Thirty plants were dug up and transplanted into sterilized soil with one plant/pot at the PGC, and were randomly assigned as herbivory or control uninjured plants in our VOC induction experiment.

\subsection{Leaf herbivory}

One leaf of each plant was put into a plastic cylinder ( $20 \mathrm{~cm}$ long, $6 \mathrm{~cm}$ diameter). On the top and bottom of the plastic cylinder, two holes were made to surround the inserted leaf petiole. One male-female (collected in copula') pair of newly-emerged G. viridula adults was introduced in each cylinder. Herbivory treatment plants had one leaf subjected to feeding for $24 \mathrm{hr}$, while control uninjured plants received a plastic cylinder on one leaf with no beetles for the same duration.

\subsection{Volatile collection system}

Volatiles were collected simultaneously from Nalophan (odour and taste-free cooking bags made of a plastic film resistant in the temperature range from $-60^{\circ} \mathrm{C}$ to $+220^{\circ} \mathrm{C}$ ) from the single enclosed leaf on each $R$. confertus plant. The apparatus allowed the collection of odours from 4 plants at the same time, and each collection period lasted $3 \mathrm{hr}$ (from 10 a.m. to 1 p.m.). Thus, 8 days were required (collections occurred from two empty Nalophan bags for a total of 32 measurements), and treatment plants were randomly assigned across collection days. A volatile collector trap (6.35-mm-OD (outside diameter), 76-mm-long glass tube; Analytical Research Systems, Inc., Gainesville, Florida, USA) containing $30 \mathrm{mg}$ of Super-Q (Alltech Associates, Inc., Deerfield, Illinois, USA) adsorbent was inserted into each of 4 Tygon tubes (connection between airflow meter and collector trap). Purified, humidified air was delivered at a rate of $1.01 \cdot \mathrm{min}^{-1}$ over the plants, and a vacuum pump sucked $20 \%$ less $\left(0.81 \cdot \mathrm{min}^{-1}\right)$ to avoid collecting odours from any gap of the system. Volatiles were collected from one leaf 
(three hr collections sequence).

\subsection{Analytical methods}

Plant VOCs. Volatiles were eluted from the Super-Q collection trap with $225 \mu \mathrm{l}$ of hexane containing $7 \mathrm{ng}$ of decane as an internal standard. Volatiles were analyzed by coupled gas chromatography-mass spectrometry (GC-MS). The compounds were ordered on the chromatogram by their retention time (Fig. 1). A GC Perkin Elmer AutoSystem XL was fitted with a 30-m DB-5MS capillary column (0.25-mm-ID, $0.25 \mu \mathrm{m}$ film thickness; Restek, Bellefonte, PA, USA). The temperature program increased the chromatography oven temperature from $40^{\circ} \mathrm{C}$ to $200^{\circ} \mathrm{C}$ at $5^{\circ} \mathrm{C} \cdot \mathrm{min}^{-1}$. Plant volatile identification was verified with authentic standards (Sigma-Aldrich, St. Louis, MO, USA) that had the same GC retention times and mass spectra. Peaks were integrated directly from the GC-chromatogram, and compared to the internal standard peak to determine concentrations.

\subsection{Analytical methods: Insect behaviour}

There were six VOCs chosen for Y - tube experiments; three GLVs ( $(Z)-3$-hexenal = $(Z)$-HAL, $(Z)-3$-hexenol $=$ $(\mathrm{Z})-3-\mathrm{HOL},(\mathrm{Z})-3$-hexen-1-yl acetate $)=(\mathrm{Z})-3-\mathrm{HAC}$ ), and three terpenes (linalool $=$ LIN, $\beta$-caryophyllene $=$ $\beta$-CAR, $\beta$-farnesene $=ß$-FAR). All six of these VOCs were significantly induced by an injured $R$. confertus leaf after G. viridula herbivory. The Y-tube system used was similar to that described by Piesik et al. (2008). To screen behavioural activity of the volatile compounds identified from $R$. confertus, commercially available compounds (Sigma-Aldrich Chemical Co. Inc.) were tested at four concentrations (1, 5, 25, $125 \mathrm{ng} \cdot \mathrm{min}^{-1}$ ) and compared to the absence $\left(0 \mathrm{ng} \cdot \mathrm{min}^{-1}\right)$ of each compound. We used $\mathrm{ng} \cdot \mathrm{min}^{-1}$ because behavioral trials lasted on the scale of min, not hr. Twenty G. viridula adults were used of each sex for each concentration of all tested compounds, involved newly emerged adults $\leq 1 \mathrm{~d}$ old, and each insect was tested once.

\subsection{Statistical analyses}

None of the six VOCs collected from R. confertus leaves were detected from collections of Nalophan bags alone. Two sample t-tests (19 df) not assuming equal variances between the injury and control treatments were conducted for each VOC using MS Excel 2003 (data analysis option).

With the behavioural response data, an initial G-test of independence was performed on pooled count data for both sexes and analyzed across the five test doses $\left(0,1,5,25\right.$, and $\left.125 \mathrm{ng} \cdot \mathrm{min}^{-1}\right)$ of individuals that went to the compound side or the side with hexane solvent alone. After this, separate G-tests were performed to examine whether female and/or male G. viridula had significant dose responses to each compound. Finally, individual chi-square tests for small sample sizes (Sokal and Rohlf, 1995) were performed for each sex at each dose for each compound against an expected 10:10 ratio (if choosing an arm is independent of the presence of a VOC). Frequency data analyses were performed using the statistical package SAS 9.2 (SAS Institute, 2007).

\section{Results and discussion}

\section{1}

We identified six VOCs released by an injured $R$. confertus leaf after $G$. viridula herbivory. These were three GLVs ((Z)-3-HAL, (Z)-3-HOL, (Z)-3-HAC) and three terpenes (LIN, B-CAR, B-FAR (R/S enantiomers not identified)) (Fig. 1). Injured $R$. confertus leaves released significantly much higher concentrations $(>66 \mathrm{x})$ of each VOC relative to uninjured control leaves (Fig. 2). The control plants produced small or undetectable (given equipment limitations) amounts of these six VOCs (Fig. 2). Beetle behaviour in Y-tube. No significant female or male G. viridula attraction or repellence occurred with (Z)-3-HOL (Table 1). No significant doses responses were detected for B-CAR with pooled data of both sexes as well as females alone, while males alone had a significant dose response; however, no significant male attraction or repellence was detected at any $\beta$-CAR dose (Table 1). Yet, (Z)-3-HAL, (Z)-3-HAC, LIN, and B-FAR had significant dose responses (Table 1). Females and males were attracted to low concentrations (1 and $5 \mathrm{ng} \cdot \mathrm{min}^{-1}$ ) of (Z)-3-HAL and (Z)-3-HAC. In contrast, both females and males were repelled by the y-tube arm that had the highest dose (125 $\left.\mathrm{ng} \cdot \mathrm{min}^{-1}\right)$ of $(\mathrm{Z})-3-\mathrm{HAL}$, (Z)-3-HAC, B-FAR (also $25 \mathrm{ng} \cdot \mathrm{min}^{-1}$ ), and LIN (Table 1).

\section{2}

Six VOCs were induced $\geq 66 \mathrm{x}$ by $R$. confertus after $G$. viridula herbivory on a single leaf. Two GLVs ((Z)-3-HAL and (Z)-3-HAC) and one terpene (LIN) had quantitative induction after injury, while a third GLV $((\mathrm{Z})-3-\mathrm{HOL})$ and the other two terpenes (ß-CAR and $\beta-\mathrm{FAR})$ had essentially qualitative induction (concentrations of controls not significantly distinguishable from zero). VOCs may be involved in direct and indirect plant defences against herbivores or pathogens (Dudareva et al., 2006; Thompson \& Goggin, 2006; Shiojiri \& Karban, 2008). The six VOCs detected in our study are among commonly induced GLVs and terpenes 
after insect herbivory on other plants (Dudareva et al., 2006). Farag \& Paré (2002) demonstrated that tomato plants (Lycopersicon esculentum) with insect feeding released both locally and systemically elevated levels of GLVs and other VOCs. Also, Engelberth et al. (2004) showed that GLVs prime corn plant defences against herbivorous insects.

Subsequent testing showed that herbivorous G. viridula had little or no response to (Z)-3-HOL and (E)-B-CAR. In contrast, both sexes of $G$. viridula were attracted to a concentration $\left(5 \mathrm{ng} \cdot \mathrm{min}^{-1}=300 \mathrm{ng} \cdot \mathrm{hr}^{-1}\right)$ of (Z)-3-HAL and $(\mathrm{Z})-3$-HAC that was at the same scale as the emitted concentrations measured from single injured $R$. confertus leaves. This suggests that $G$. viridula might use GLVs from injured leaves to find lightly injured (single leaf) host plants, perhaps to aid with food and mate searching. However, at a much higher concentration (125 ng $\min ^{-1}=7500 \mathrm{ng} \cdot \mathrm{hr}^{-1}$ ) of (Z)-3-HAL, (Z)-3-HAC, and the terpenes LIN and (E)-B-FAR, G. viridula were repelled by (or avoided) those VOCs under y-tube choice conditions. The G. viridula orientation results to each single VOC closely match those of a congeneric specialist $R$. confertus herbivore, G. polygoni (Piesik et al. In Review), except only G. viridula was repelled by the highest LIN dose. The trend with these two beetle congeners suggests that individuals would avoid highly injured plants in the field, since it would take many injured leaves on a plant to reach such a concentration, which would need to be tested. Also, both Gastrophysa spp. might respond to $R$. confertus VOCs induced by conspecific herbivory similarly as that from a congener, requiring field testing.

Insect attraction to plant induced VOCs after herbivory might be helpful in developing a lure to monitor field production. Dose responses are needed to suggest which concentrations might work best with such field lures. Bruce et al. (2005) noticed insect exposure to blends of compounds in the same ratios as those produced by plants might be required for attraction or repellency. Our approach differed by examining responses of herbivores to each VOC separately. Further investigation is needed using complete $R$. confertus induced VOC bouquets and various mixtures of $2^{+}$VOCs for responses from herbivorous Gastrophysa spp. orientation responses. This work can be used to suggest which field VOC lures could be used to draw biological control agents to target weed plants at initial releases, or draw individuals to bad weed infestations using VOCs once an agent has become established. Yet, understanding how other herbivores and herbivore natural enemies are attracted/repelled by plant induced VOCs in the field is needed to provide a more complete ecological understanding of the importance of VOC induction as relates to herbivory (Ninkovic et al., 2003, Cook et al., 2007, Dicke \& Baldwin, 2010).

\section{Acknowledgements}

Portions of this research were supported with funds provided by the Marie-Curie Foundation (FLORDETERSIGNALS, contract number MERG-CT-2007-200265), European Re-integration Grants (ERG) entitled, 'Silene floral and deterrent signals'.

\section{References}

Baldwin I.T., Halitschke R., Kessler A. \& Schittko U. (2001). Merging molecular and ecological approaches in plant-insect interactions. Current Opinion in Plant Biology, 4, 351-358. http://dx.doi.org/10.1016/S1369-5266(00)00184-9

Bruce T.J.A., Wadhams L.J. \& Woodcock C.M. (2005). Insect host location: a volatile situation. Trends in Plant Science, 10, 269-274. http://dx.doi.org/10.1016/j.tplants.2005.04.003

Cavers P.B. \& Harper J.L. (1964). Biological flora of the British Isles, Rumex obtusifolius L. and Rumex crispus L. Ecology, 52, 737-766. http://dx.doi.org/10.2307/2257859

Cook S.M., Khan Z.R. \& Pickett J.A. (2007). The use of push-pull strategies in integrated pest management. Annual Review of Entomology, 52, 375-400. http://dx.doi.org/10.1146/annurev.ento.52.110405.091407

De Moraes C.M., Mescher M.C. \& Tumlinson J.H. (2001). Caterpillar-induced nocturnal plant volatiles repel nonspecific females. Nature, 410, 577-580. http://dx.doi.org/10.1038/35069058

Dicke M. \& Baldwin I.T. (2010). The evolutionary context for herbivore-induced plant volatiles: beyond the 'cry for help'. Trends in Plant Science, 15, 167-174. http://dx.doi.org/10.1016/j.tplants.2009.12.002

Dudareva N., Negre F., Nagegowda D.A. \& Orlova I. (2006). Plant Volatiles: Recent Advances and Future Perspectives. Critical Reviews in Plant Sciences, 25, 417-440. http://dx.doi.org/doi:10.1080/07352680600899973

Engelberth, J., Alborn, H.T., Schmelz, E.A. \& Tumlinson, J.H. (2004). Airborne signals prime plants against insect herbivore attack. Plant Biology, 101, 1781-1785.

Farag M.A. \& Paré P.W. (2002). C6 - green leaf volatiles trigger local and systemic VOC emission in tomato. 
Phytochemistry, 61, 545-554. http://dx.doi.org/10.1016/S0031-9422(02)00240-6

Heil M. (2008). Indirect defence via tritrophic interactions. New Phytologist, 178, 41-61. http://dx.doi.org/10.1111/j.1469-8137.2007.02330.x

Honek A., Jarosik V. \& Martinkova Z. (2003). Effect of temperature on development and reproduction in Gastrophysa viridula (Coleoptera: Chrysomelidae). European Journal of Entomology, 100, 295-300.

Martinkova Z. \& Honek A. (2004). Gastrophysa viridula (Coleoptera: Chrysomelidae) and biocontrol of Rumex - a review. Plant Soil and Environment, 50, 1-9.

Ninkovic V., Ahmed E., Glinwood R. \& Pettersson J. (2003). Effects of two types of semiochemical on population development of the bird cherry oat aphid Rhopalosiphum padi in a barley crop. Agricultural and Forest Entomology, 5, 27-33. http://dx.doi.org/10.1046/j.1461-9563.2003.00159.x

Piesik D. \& Wenda - Piesik A. (2005). Gastroidea viridula Deg. potential to control mossy sorrel (Rumex confertus Willd.). Journal of Plant Protection Research, 45, 63-71.

Piesik D., Weaver D.K., Runyon J.B., Buteler M., Peck G.E. \& Morrill W. L. (2008). Behavioural responses of wheat stem sawflies to wheat volatiles. Agricultural and Forest Entomology, 10, 245-253. http://dx.doi.org/10.1111/j.1461-9563.2008.00380.x

Schoonhoven L.M., Van Loon J.J.A. \& Dicke, M. (2005). Insect-Plant Biology. Oxford University Press.

Shiojiri K. \& Karban R. (2008). Vascular systemic induced resistance for Artemisia cana and volatile communication for Artemisia douglasiana. American Midland Naturalist, 159, 468-477. http://dx.doi.org/10.1674/0003-0031(2008)159[468:VSIRFA]2.0.CO;2

Sokal R.R. \& Rohlf F.J. (1995). Biometry: The Principles and Practice of Statistics in Biological Research. Freeman W.H. and Co. New York. pp.887.

Thaler J.S., Karban R., Ullman D.E., Boege K. \& Bostock R.M. (2002). Cross-talk between jasmonate and salicylate plant defense pathways: effects on several plant parasites. Oecologia, 131, 227-235. http://dx.doi.org/10.1007/s00442-002-0885-9

Thompson G.A. \& Goggin F.L (2006). Transcriptomics and functional genomics of plant defence induction by phloem-feeding insects. Journal of Experimental Botany, 57, 755-766. http://dx.doi.org/10.1093/jxb/erj135 
Table 1. Effect of synthetic (Z)-3-HAL, (Z)-3-HOL, (Z)-3-HAC, LIN, $\beta$-CAR, and $\beta$-FAR volatiles $\left(\mathrm{ng} \cdot \mathrm{min}^{-1}\right)$ on G. viridula adult female and male behavior

\begin{tabular}{|c|c|c|c|c|c|c|c|c|}
\hline \multirow[b]{2}{*}{$\begin{array}{l}\text { Name } \\
\text { of compound }\end{array}$} & \multirow[b]{2}{*}{ Dose } & \multicolumn{3}{|c|}{ No. of females } & \multicolumn{4}{|c|}{ No. of males } \\
\hline & & $n g \cdot \min ^{-1}$ & $+{ }^{4}$ & $-{ }^{5}$ & $\chi^{2(1)}$ & $+{ }^{4}$ & $-{ }^{5}$ & $\chi^{2(1)}$ \\
\hline & control & 0.0 & 9 & 11 & $0.05 \mathrm{~ns}$ & 8 & 12 & $0.45 \mathrm{~ns}$ \\
\hline & 1 & 1 & 15 & 5 & $4.05^{*}(a)^{3}$ & 15 & 5 & $4.05 *(a)^{3}$ \\
\hline & 2 & 5 & 17 & 3 & $8.45^{* *}(a)^{3}$ & 12 & 8 & $0.45 \mathrm{~ns}$ \\
\hline \multirow{2}{*}{ (Z)-3-HAL } & 3 & 25 & 7 & 13 & $1.25 \mathrm{~ns}$ & 14 & 6 & $2.45 \mathrm{~ns}$ \\
\hline & 4 & 125 & 3 & 17 & $8.45 * *(r)^{2}$ & 5 & 15 & $4.05 *(r)^{2}$ \\
\hline \multirow[t]{4}{*}{$\mathrm{G}_{4 \mathrm{df}}=35 * * * *$} & & & $\mathrm{G}_{4 \mathrm{df}}$ & $=29 * * * *$ & & $\mathrm{G}_{4 \mathrm{df}}$ & $=14.7^{* *}$ & \\
\hline & control & 0.0 & 7 & 13 & $1.25 \mathrm{~ns}$ & 12 & 8 & $0.45 \mathrm{~ns}$ \\
\hline & 1 & 1 & 12 & 8 & $0.45 \mathrm{~ns}$ & 13 & 7 & $1.25 \mathrm{~ns} 2$ \\
\hline & 5 & 7 & 13 & $1.25 \mathrm{~ns}$ & 9 & 11 & $0.05 \mathrm{~ns}$ & \\
\hline \multirow[t]{2}{*}{ (Z)-3-HOL } & 3 & 25 & 10 & 10 & $0.05 \mathrm{~ns}$ & 13 & 7 & $1.25 \mathrm{~ns} 4$ \\
\hline & 125 & 11 & 9 & $0.05 \mathrm{~ns}$ & 10 & 10 & $0.05 \mathrm{~ns}$ & \\
\hline \multirow[t]{4}{*}{$\mathrm{G}_{4 \mathrm{df}}=4.9^{\mathrm{ns}}$} & & & $\mathrm{G}_{4 \mathrm{df}}$ & $=4.3^{\mathrm{ns}}$ & & $\mathrm{G}_{4 \mathrm{df}}$ & $=2.7^{\mathrm{ns}}$ & \\
\hline & control & 0.0 & 9 & 11 & $0.05 \mathrm{~ns}$ & 12 & 8 & $0.45 \mathrm{~ns}$ \\
\hline & 1 & 1 & 16 & 4 & $6.05^{*}(\mathrm{a})^{3}$ & 15 & 5 & $4.05 *(a)^{3}$ \\
\hline & 2 & 5 & 17 & 3 & $8.45^{* *}(a)^{3}$ & 16 & 4 & $6.05^{*}(\mathrm{a})^{3}$ \\
\hline \multirow[t]{2}{*}{ (Z)-3-HAC } & 3 & 25 & 8 & 12 & $0.45 \mathrm{~ns}$ & 14 & 6 & $2.45 \mathrm{~ns}$ \\
\hline & 4 & 125 & 2 & 18 & $11.25^{* * *}(\mathrm{r})^{2}$ & 5 & 15 & $4.05^{*}(r)^{2}$ \\
\hline \multirow[t]{4}{*}{$\mathrm{G}_{4 \mathrm{df}}=46^{* * * *}$} & & $\mathrm{G}_{4 \mathrm{df}}$ & $=34 * * * *$ & & & $\mathrm{G}_{4 \mathrm{df}}$ & $=16.5^{* *}$ & \\
\hline & control & 0.0 & 9 & 11 & $0.05 \mathrm{~ns}$ & 12 & 8 & $0.45 \mathrm{~ns}$ \\
\hline & 1 & 1 & 8 & 12 & $0.45 \mathrm{~ns}$ & 8 & 12 & $0.45 \mathrm{~ns}$ \\
\hline & 2 & 5 & 10 & 10 & $0.05 \mathrm{~ns}$ & 10 & 10 & $0.05 \mathrm{~ns}$ \\
\hline \multirow[t]{2}{*}{ LIN } & 3 & 25 & 7 & 13 & $1.25 \mathrm{~ns}$ & 11 & 9 & $0.05 \mathrm{~ns}$ \\
\hline & 4 & 125 & 3 & 17 & $8.45^{* *}(\mathrm{r})^{2}$ & 4 & 16 & $6.05^{*}(\mathrm{r})^{2}$ \\
\hline \multirow[t]{4}{*}{$\mathrm{G}_{4 \mathrm{df}}=14 * *$} & & $\mathrm{G}_{4 \mathrm{df}}=$ & $=6.8^{\mathrm{ns}}$ & & & $\mathrm{G}_{4 \mathrm{df}}$ & $=8.5^{\mathrm{ns}}$ & \\
\hline & control & 0.0 & 8 & 12 & $0.45 \mathrm{~ns}$ & 11 & 9 & $0.05 \mathrm{~ns}$ \\
\hline & 1 & 1 & 8 & 12 & $0.45 \mathrm{~ns}$ & 7 & 13 & $1.25 \mathrm{~ns}$ \\
\hline & 2 & 5 & 12 & 8 & $0.45 \mathrm{~ns}$ & 14 & 6 & $2.45 \mathrm{~ns}$ \\
\hline \multirow[t]{2}{*}{$\beta$-CAR } & 3 & 25 & 10 & 10 & $0.05 \mathrm{~ns}$ & 6 & 14 & $2.45 \mathrm{~ns}$ \\
\hline & 4 & 125 & 11 & 9 & $0.05 \mathrm{~ns}$ & 7 & 13 & $1.25 \mathrm{~ns}$ \\
\hline \multirow[t]{4}{*}{$\underline{\mathrm{G}}_{4 \mathrm{df}}=7.6^{\mathrm{ns}}$} & & $\mathrm{G}_{4 \mathrm{df}}=$ & $=2.6^{\mathrm{ns}}$ & & & $\mathrm{G}_{4 \mathrm{df}}$ & $=9.4^{*}$ & \\
\hline & control & 0.0 & 11 & 9 & $0.05 \mathrm{~ns}$ & 9 & 11 & $0.05 \mathrm{~ns}$ \\
\hline & 1 & 1 & 6 & 14 & $2.45 \mathrm{~ns}$ & 11 & 9 & $0.05 \mathrm{~ns}$ \\
\hline & 2 & 5 & 8 & 12 & $0.45 \mathrm{~ns}$ & 12 & 8 & $0.45 \mathrm{~ns}$ \\
\hline \multirow[t]{2}{*}{$\beta$-FAR } & 3 & 25 & 4 & 16 & $6.05^{*}(\mathrm{r})^{2}$ & 5 & 15 & $4.05^{*}(\mathrm{r})^{2}$ \\
\hline & 4 & 125 & 2 & 18 & $11.25^{* * *}(\mathrm{r})^{2}$ & 3 & 17 & $8.45 * *(\mathrm{r})^{2}$ \\
\hline $\mathrm{G}_{4 \mathrm{df}}=22 * * *$ & & $\mathrm{G}_{4 \mathrm{df}}=$ & $=11.9^{*}$ & & & $\mathrm{G}_{4 \mathrm{df}}$ & $=13.2 * *$ & \\
\hline
\end{tabular}

Legend:

(1) level of significance (ns-not significant), $\left({ }^{*} \mathrm{p}<0.05\right),\left({ }^{* *} \mathrm{p}<0.01\right),\left({ }^{* * *} \mathrm{p}<0.001\right),\left({ }^{* * * *} \mathrm{p}<0.0001\right)$

${ }^{2} \mathrm{r}$ - repellent,

${ }^{3} \mathrm{a}$ - attractant,

${ }^{4}+\mathrm{Y}$ - tube arm with tested amount of the compound, volatile diluted in hexane emitted from filter paper,

${ }^{5}-\mathrm{Y}$ - tube arm only with hexane emitted from filter paper. 


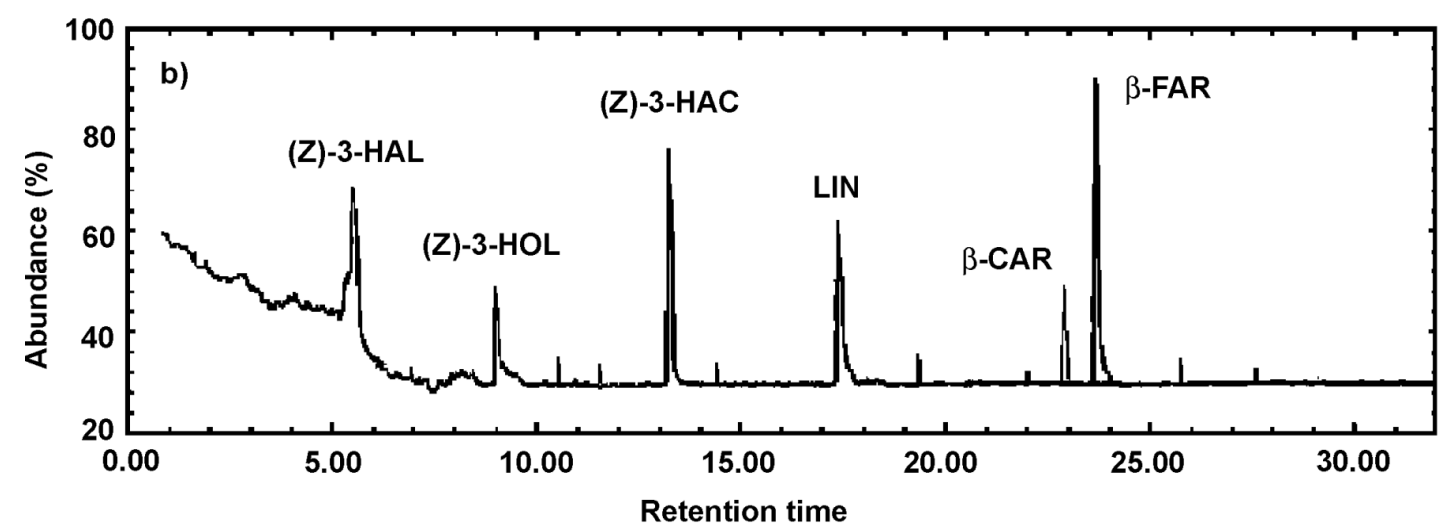

Figure 1. A chromatograph showing collected volatiles, named above each peak

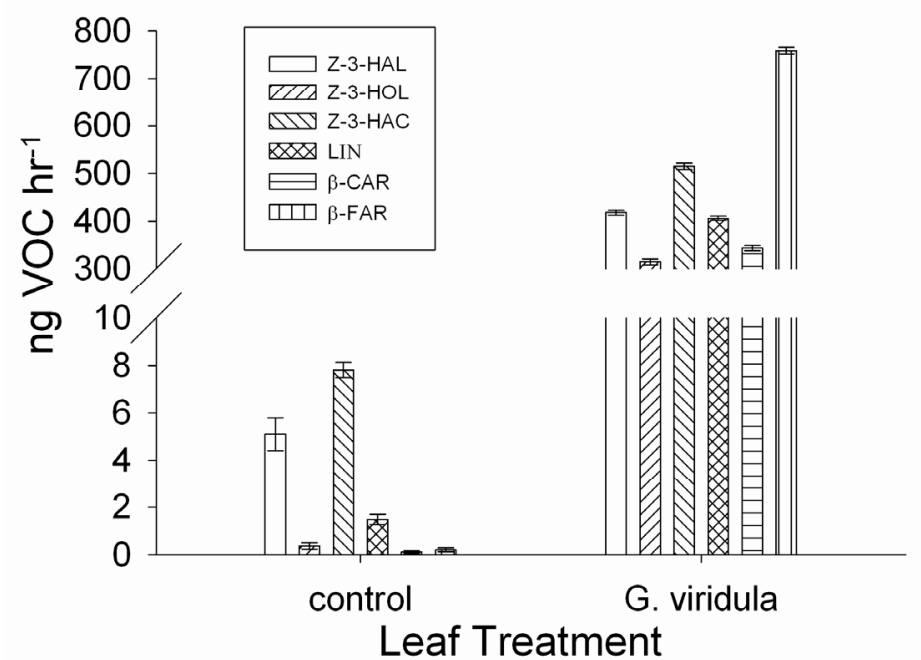

Figure 2. The mean $( \pm 1 \mathrm{SE})$ is shown for control and G. viridula herbivory leaves for each of the six VOCs. For the unequal variance T-tests, the smallest t-statistic was 52 ( $\mathrm{p}<<0.00001)$ for (Z)-3-HOL 